\title{
Atmospheric boundary layer characteristics during the BOBMEX-Pilot experiment
}

\author{
G S Bhat ${ }^{1}$, S Ameenulla ${ }^{1}$, M Venkataramana ${ }^{2}$ and K Sengupta ${ }^{2}$ \\ ${ }^{1}$ Centre for Atmospheric and Oceanic Sciences, Indian Institute of Science, Bangalore 560 012, India \\ ${ }^{2}$ Space Physics Laboratory, Vikram Sarabhai Space Centre, Trivandrum, India
}

The atmospheric boundary layer characteristics observed during the BOBMEX-Pilot experiment are reported. Surface meteorological data were acquired continuously through an automatic weather monitoring system and manually every three hours. High resolution radiosondes were launched to obtain the vertical thermal structure of the atmosphere. The study area was convectively active, the SSTs were high, surface air was warm and moist, and the surface air moist static energy was among the highest observed over the tropical oceans. The mean sea air temperature difference was about $1.25^{\circ} \mathrm{C}$ and the sea skin temperature was cooler than bucket SST by $0.5^{\circ} \mathrm{C}$. The atmospheric mixed layer was shallow, fluctuated in response to synoptic conditions from $100 \mathrm{~m}$ to $900 \mathrm{~m}$ with a mean around $500 \mathrm{~m}$.

\section{Introduction}

Many synoptic systems that produce rainfall over the Indian subcontinent form and intensify over the Bay of Bengal. The frequency of occurrence of convective systems over the Bay of Bengal is among the highest in the world during the summer months. The physical processes responsible for this have not been clearly understood. The Bay of Bengal has many special oceanographic features as well. For example, the variation in the sea surface temperature (SST) of $1^{\circ} \mathrm{C}$ to $2^{\circ} \mathrm{C}$ over a period of 2 to 4 weeks (intraseasonal oscillation) is larger than the inter annual variation of $0.5^{\circ} \mathrm{C}$ (Premkumar et al 2000). The head Bay is influenced by the large volume of freshwater discharge from rivers, which is not the case in the central and southern Bay, thus giving rise to strong north-south gradient in salinity. Thus, the Bay of Bengal has certain unique features which make it an exciting place for scientific investigations.

There have been three major summer monsoon experiments in the Bay of Bengal in the past. The first two experiments, called MONSOON-77 and MONEX79 , were carried out more than two decades back and with international collaboration. MONSOON-77 involved four USSR ships forming a polygon over the
Bay of Bengal centered at $17^{\circ} \mathrm{N} 89^{\circ} \mathrm{E}$ during 11 th 19th August 1977. The observations included upper air soundings every six hours (00, 06, 12 and 18 GMT). A trough formed over the head Bay on August 16th which developed into a depression on August 19th. Thus, the experiment provided data that enabled the study of the changes in the horizontal wind fields, vertical velocity and largescale heat and moisture budgets between disturbed and undisturbed conditions in the Bay (e.g., Mohanty and Das 1986). MONEX-79 measurements over the Bay involved mainly four Russian ships forming a stationary polygon centered at $16.2^{\circ} \mathrm{N} 89.5^{\circ} \mathrm{E}$ during the period 11 th -24 th July 1979 . Observations from the ships included upper air soundings two times a day (00 and 12 GMT), surface air temperature, dew point temperature, wind speed and direction, cloud amount and sea surface pressure. This period happened to be the break/weak monsoon period over the region and disturbed conditions could not be observed. In addition to ships, an aircraft equipped with dropwind sonde was used during MONEX-79. The third experiment, MONTBLEX-90, was carried out on board the Indian research vessel ORV Sagar Kanya during August - September 1990 in the head Bay.

Keywords. Marine boundary layer; air-sea coupling. 
The above experiments have provided information on the changes in the wind fields, surface fluxes and large scale heat and moisture budgets, between disturbed and undisturbed conditions in the Bay (Mohanty and Das 1986; Saha and Saha 1988; Rao et al 1993; Murty et al 1996; Sarma et al 1997; Sanilkumar et al 1994; Moshonkin and Harenduprakash 1991). These experiments had certain limitations too. The dominant signal in the atmosphere and the SST of the Bay is on the intraseasonal scale of two to four weeks and the ocean and the atmosphere are strongly coupled on this time scale (Premkumar et al 2000). The time series in the earlier experiments are either too short $(\sim 10$ days $)$ or the ships were continuously moving to reveal clearly the intraseasonal time scales. Further, the surface fluxes were derived using empirical relations and bulk aerodynamic formulae, and solar and longwave radiation were not directly measured. The soundings had typical vertical resolution of $25-50 \mathrm{mb}$, which is not sufficient to study the structure of the marine atmospheric boundary layer.

There are several outstanding questions regarding both the atmosphere and the ocean over the BoB, and a field experiment, called the Bay of Bengal Monsoon Experiment (BOBMEX) was proposed under ICRP. The background and objectives of BOBMEX as well as the BOBMEX-Pilot experiment are given in the paper by Sikka and Sanjeeva Rao in this issue.

In this paper, we present the surface meteorological parameters, the atmospheric mixed layer height and the sea surface temperature (SST) observed during the Pilot experiment. The Pilot experiment was carried out on board ORV Sagar Kanya during October - November 1998. The cruise track is shown in figure 1; it started from Marmugao on October 23rd and ended at Tuticorin on November 12th. The first stationary time series station was located at $7^{\circ} \mathrm{N} 87^{\circ} \mathrm{E}$ for two days on October 30th and 31st. The second time series station was at $10^{\circ} \mathrm{N} 87^{\circ} \mathrm{E}$ for two days (2nd - 3rd November), and the last time series station for a day was located at $13^{\circ} \mathrm{N} 87^{\circ} \mathrm{E}$ on November 5th.

\section{Experimental arrangement: Atmospheric component}

The surface micrometeorological sensors were mounted on a tower fixed to a seven meter long (horizontal) boom at the forecastle deck. Figure 2 shows a schematic of the sensor arrangement on the tower. Wind, temperature, humidity, solar and longwave radiation sensors were installed on the tower and the data from these sensors were continuously acquired. The characteristics of the sensors whose data are reported in this paper are given in table 1 . Both fast response (frequency response $10 \mathrm{~Hz}$ ) and

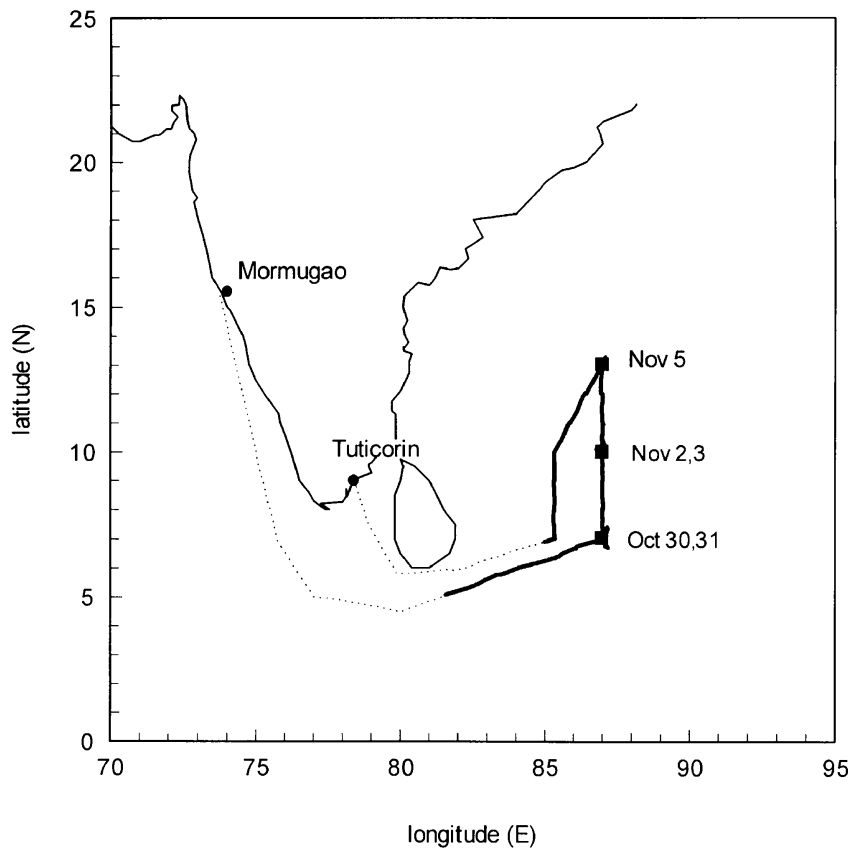

Figure 1. BOBMEX-Pilot cruise track. The solid box symbols refer to the locations of time series stations.

slow response (frequency response slower than $1 \mathrm{~Hz}$ ) were used. Output of some of the sensors were RS232 digital signals (e.g., sonic anemometer) whereas others were analogue signals. Digital signals were directly fed to the RS232 ports through a multi-serial port add-on PC card. For each analog signal, a variable gain differential input with a small filter facility was provided. The analog voltage signals were routed to the data acquisition system. The Data Acquisition System was a 12 bit system having 16 analogue input channels (DAQbook model 120, manufactured by M/s Iotech Inc., USA). The digitized signals from the DAQbook were fed to the computer through a parallel port connection. A pentium machine working on Windows 95 was used for acquiring and storing the data.

High vertical resolution radiosondes manufactured by AIR (Atmospheric Instrumentation Research Inc., USA) were launched using $300 \mathrm{~g}$ balloons. These provided the temperature and humidity values as a function of pressure every 5 seconds (see table 1 for sensor characteristics). The ascent rate was adjusted to $3-4 \mathrm{~m} / \mathrm{s}$ by controlling the amount of hydrogen gas filled in the balloon to provide a vertical resolution between 15 and 20 meters.

The ship position (latitude, longitude and heading), surface pressure, dry bulb and wet bulb temperatures (psychrometer), and SST (bucket temperature) were recorded every three hours manually. The sea surface skin temperature was measured by an infrared thermometer (henceforth, the infrared thermometer reading is referred to as SKINSST). 

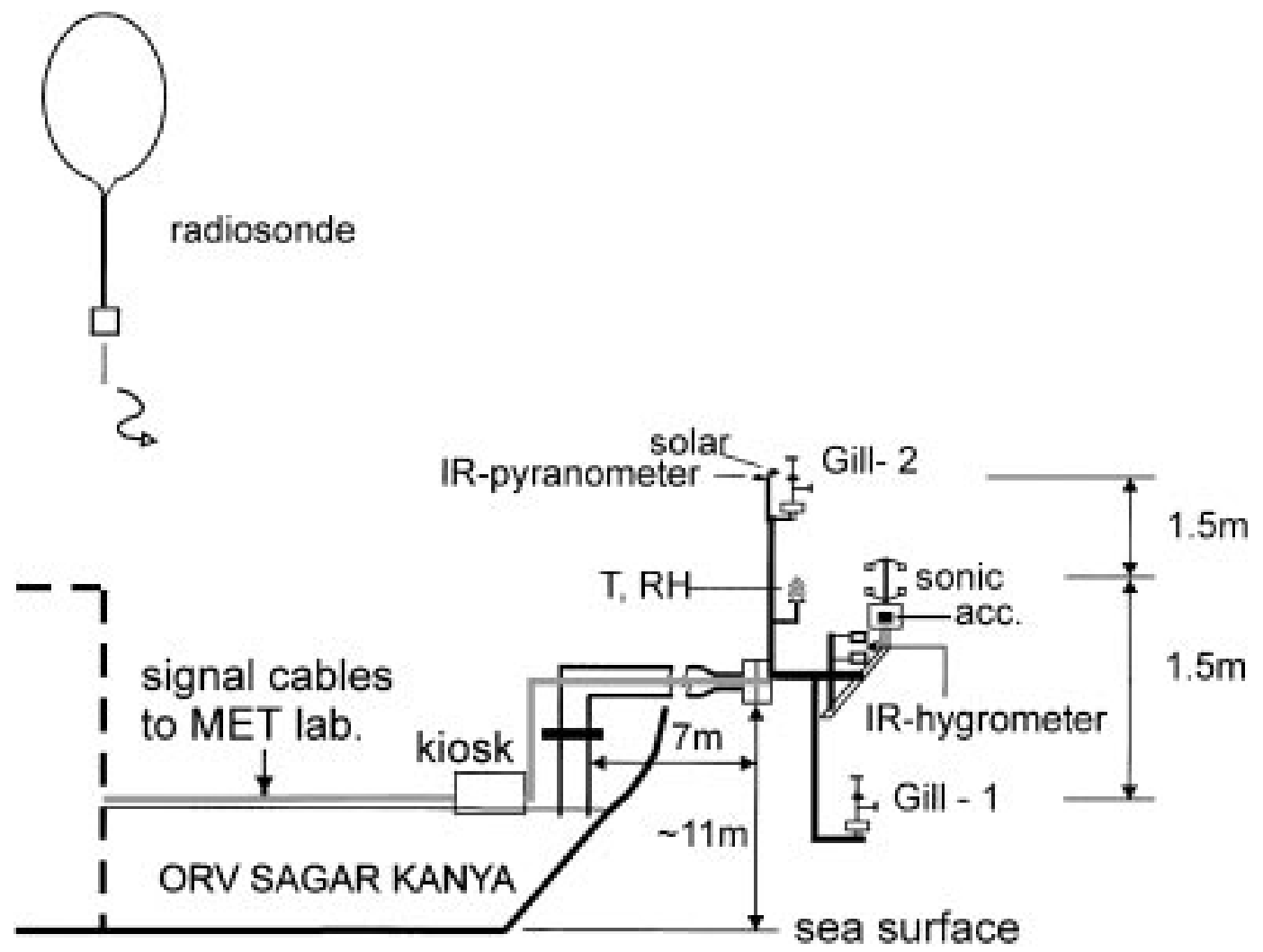

Figure 2. A schematic of the sensor arrangement on board ORV Sagar Kanya during the Pilot experiment.

Table 1. Specifications of the Instruments used during the BOBMEX-Pilot experiment.

\begin{tabular}{|c|c|c|c|c|}
\hline Sensor/Instrument & Parameter & Make & Accuracy & Sampling rate \\
\hline Sonic Anemometer & $\begin{array}{l}\text { Wind Component }(u, v, w) \\
\text { Temperature }\end{array}$ & METEK, Germany & $\begin{array}{c} \pm 0.1 \mathrm{~m} / \mathrm{s} \\
0.01^{\circ} \mathrm{C}\end{array}$ & $\begin{array}{l}10 \mathrm{~Hz} \\
10 \mathrm{~Hz}\end{array}$ \\
\hline Pyranometer & $\begin{array}{l}\text { Short Wave }(\% 3-3 \mu) \\
\text { Long Wave }(3-50 \mu)\end{array}$ & $\begin{array}{l}\text { Eppley Lab, USA } \\
\text { Eppley Lab, USA }\end{array}$ & $\begin{array}{l}\sim 10 \mathrm{~W} / \mathrm{m}^{2} \\
\sim 10 \mathrm{~W} / \mathrm{m}^{2}\end{array}$ & $\begin{array}{l}0.1 \mathrm{~Hz} \\
0.1 \mathrm{~Hz}\end{array}$ \\
\hline Humicap & Relative Humidity & R M Young, USA & $3 \%$ & $0.1 \mathrm{~Hz}$ \\
\hline Radiosonde & $\begin{array}{l}\text { Temperature } \\
\text { Humidity } \\
\text { Pressure }\end{array}$ & AIR Inc. USA & $\begin{array}{c}0.5^{\circ} \mathrm{C} \\
3 \% \\
1 \mathrm{mb}\end{array}$ & $\begin{array}{l}5 \mathrm{sec} \\
5 \mathrm{sec} \\
5 \mathrm{sec}\end{array}$ \\
\hline
\end{tabular}

\section{Results}

\subsection{Synoptic conditions}

The southern Bay of Bengal was convectively active during this period. INSAT-1D satellite visible imagery showed a huge cloud band over Andhra and Orissa coasts and south Tamilnadu on October 30th (see paper by Kalsi in this issue). New cloud bands formed between $65^{\circ} \mathrm{E}$ and $90^{\circ} \mathrm{E}$ around the latitude $3^{\circ} \mathrm{N}$ on October 31st, moved northward and passed over ORV Sagar Kanya on November 1st. One system intensified as it approached Tamilnadu coast on November 3rd and the entire south India experienced heavy rains for the next couple of days. Between November 2nd and 6 th, mainly clear sky and shallow cumulus clouds were observed from the ship. Few isolated cumulonimbus clouds were seen, however they did not develop into any long lasting organized convective system. Within a week after the ship moved away from the last time series station, another synoptic system was seen over the area. We expect that the conditions that prevailed during the Pilot experiment were representative of the cyclone period in the southern Bay of Bengal.

\subsection{Surface parameters}

Here, the observations taken for a period of 12 days, starting from October 28th (Julian day 301) to November 8th (Julian day 312) are presented. The thick line in figure 1 shows the corresponding observation positions. 


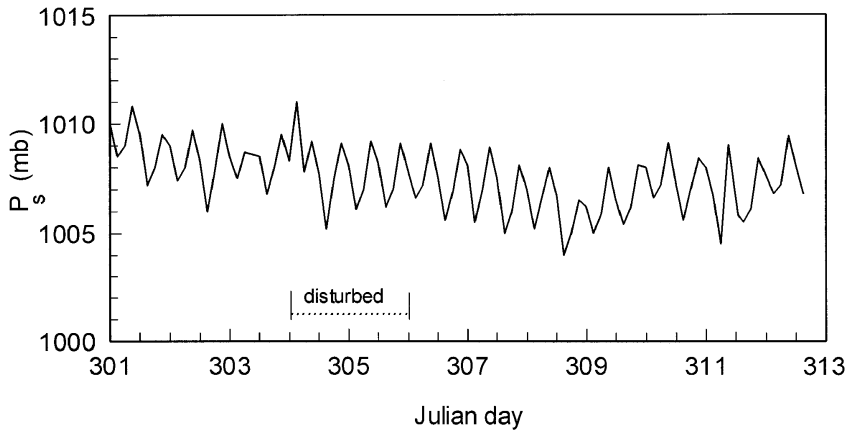

Figure 3. Variation of the surface pressure during BOBMEXPilot.

The variation of the surface pressure is shown in figure 3. The prominent feature is the semi-diurnal cycle with an amplitude of about $1.5 \mathrm{mb}$. The daily mean surface pressure decreased from $1009 \mathrm{mb}$ on day 301 to $1006 \mathrm{mb}$ on day 309 and then gradually increased. On day 305 (November 1), thick deep clouds were seen from the ship and $20 \mathrm{~mm}$ rain was recorded on board the ship. Satellite data showed that the convective system that produced this rain belonged to a long cloud band extending from $120^{\circ} \mathrm{E} 8^{\circ} \mathrm{S}$ to $85^{\circ} \mathrm{E}$ $13^{\circ} \mathrm{N}$. From the surface pressure variation, it cannot be inferred that a big tropical cloud system passed over this area. Further observations are required to understand whether this is a characteristic feature of near equatorial synoptic systems in this region or just that the ship was not at the center of convective activity. (From the satellite picture, it appeared that the ship was towards the periphery of a thick deep cloud system embedded in the synoptic system on day 305.).

The wind velocity measured by the sonic anemometer includes the component due to ship motion. The ship speed and heading were continuously monitored by a GPS system and data stored every ten minutes (facility of ORV Sagar Kanya). From the sonic anemometer and GPS data, true wind speed and true wind direction have been calculated and shown in figure 4. (The data from sensors mounted on the tower and shown in figures 4, 5,6 and 10 are five minute averages at the start of each hour.) It is observed from figure 4(a) that wind speed ranged from less than a meter per second to more than $12 \mathrm{~m} / \mathrm{s}$. Sudden jumps in the wind speed observed in figure 4(a) correspond to the passage of precipitating systems over the ship. Often, convective showers and rains were preceded by a sudden increase in the wind speed (by about $5 \mathrm{~m} / \mathrm{s}$ ) and change in wind direction. On few such occasions, wind speeds larger than $13 \mathrm{~m} / \mathrm{s}$ have been recorded for short time duration. Winds were mostly westerlies and south westerlies till day 308 and then changed over to easterly (figure 4(b)).

Figure 5(a) shows the variation of air temperature and SST. The SST shown is the bucket SST, i.e.,
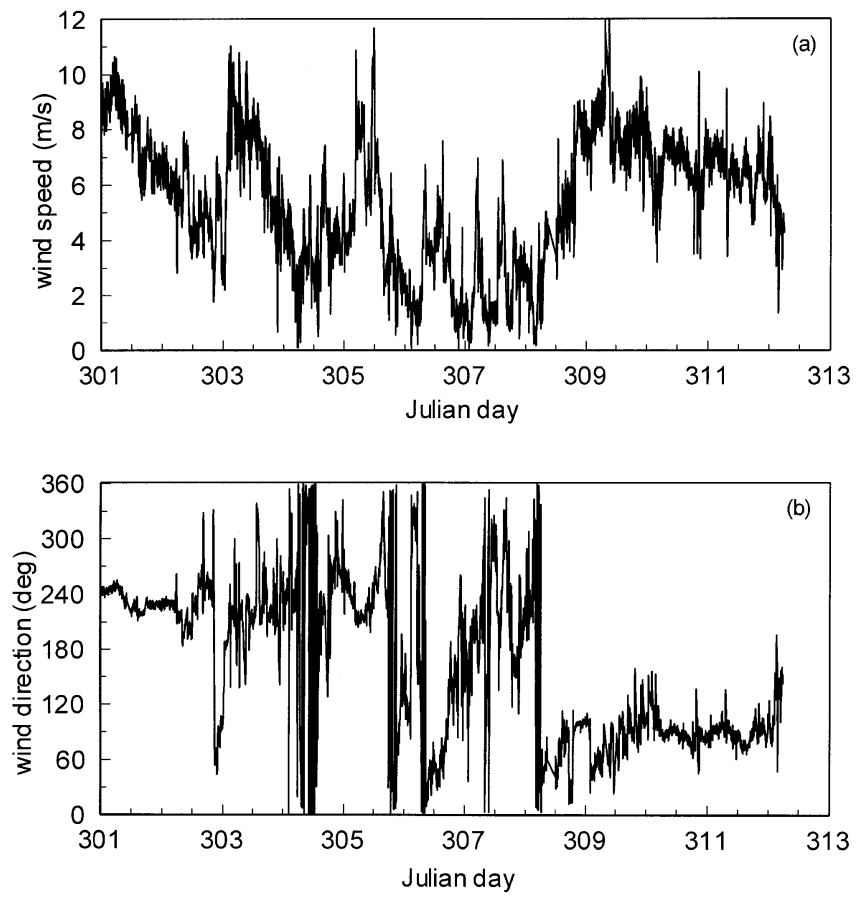

Figure 4. Variation of (a) the surface wind speed, and (b) surface wind direction.
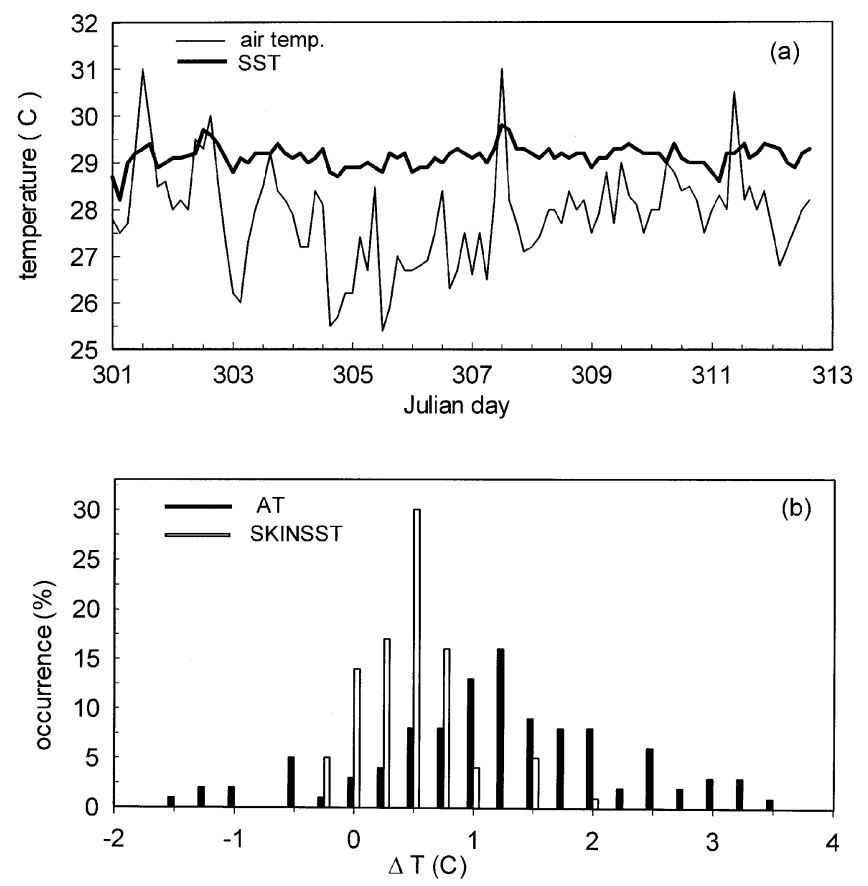

Figure 5. (a) Variation of the air temperature and SST during BOBMEX-Pilot; (b) Frequency of occurrence of the difference between SST and air temperature (AT) and SST and skin temperature (SKINSST).

temperature of the top layer of the sea water taken in a bucket. It is observed from figure 5(a) that SST was warmer than $28^{\circ} \mathrm{C}$ all the time with an average near $29^{\circ} \mathrm{C}$. Warmest SSTs were encountered on days 302 and 307. In general, the air temperature is lower than 
SST most of the time, but there were occasions when it was as warm or slightly warmer than SST (e.g., on days 301 and 302). One important parameter in the estimation of the surface sensible heat flux is the air sea temperature difference. Figure $5(\mathrm{~b})$ shows the frequency distribution of SST and air temperature difference. It is observed from this figure that sea air temperature difference varied in the $-1.5^{\circ}$ to $3.5^{\circ} \mathrm{C}$ range with a peak at $1.25^{\circ} \mathrm{C}$. Observations over tropical oceans in other parts of the globe also show sea air temperature differences typically in $1^{\circ}-2^{\circ} \mathrm{C}$ range (Slutz et al 1985; Bradley et al 1991). The negative values are associated with the measurements taken during noon hours on calm sunny days. Differences greater than +2 degree centigrade were observed when it was raining. Just before the arrival of rain and for some time following it, air temperature drops (up to four degree Celsius), whereas, SST remained nearly unaffected, thus giving rise to a larger sea air temperature difference. It may be noted that larger sea air temperature difference in the presence of increased winds enhances the surface heat flux and thus can help in the rapid recovery of the surface temperature following the rain.

Also shown in figure $5(\mathrm{~b})$ is the difference between bucket SST and surface skin temperature (SKINSST). SKINSST was measured by the IR thermometer standing on the forecastle deck at the bow of the ship where the disturbance caused by the ship's body to the sea surface was minimum. SKINSST is important in estimating the longwave radiation emitted by the ocean surface, and also in the evaporation of water. It is observed from figure 5(b) that SKINSST was cooler than the bucket SST about $95 \%$ of the time, with a peak at $0.5^{\circ} \mathrm{C}$. SKINSST is expected to be cooler than SST owing to the evaporation of water from the top most layer of the surface. On few days however, SKINSST is observed to be slightly warmer than SST; the (negative) difference is small and not more than $-0.3^{\circ} \mathrm{C}$ and occurred during the day time on sunny days. For the entire period, the mean difference between SST and SKINSST is about $0.5^{\circ} \mathrm{C}$, comparable to the values observed over the Pacific Ocean (Bradley et al 1991).

The variation of the relative humidity measured both manually (on ship deck) and automatically (on tower) is shown in figure 6 . In general, there is good agreement between the relative humidity measured by the humicap sensor (automatic) and the psychrometer (manual), and except on few occasions when the psychrometer readings were influenced by the warm ship deck, they are within $2 \%$ of each other. It is seen from figure 6 that the relative humidity was $80 \%$ or more most of the time with an average around $83 \%$, i.e., air was very rich in moisture. Values more than $90 \%$ were normally associated with drizzle and rain.

The saturation vapor pressure of water increases by about $6 \%$ for every degree centigrade increase in

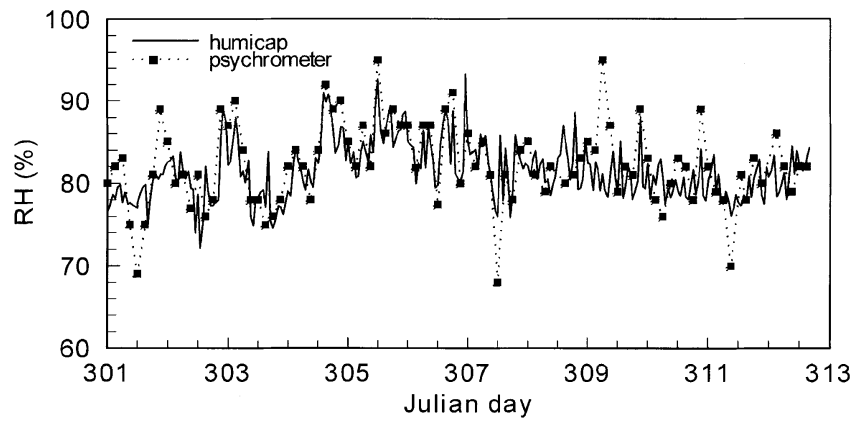

Figure 6. Variation of the surface relative humidity measured by the humicap (tower) and psychrometer (ship deck) during BOBMEX-Pilot.

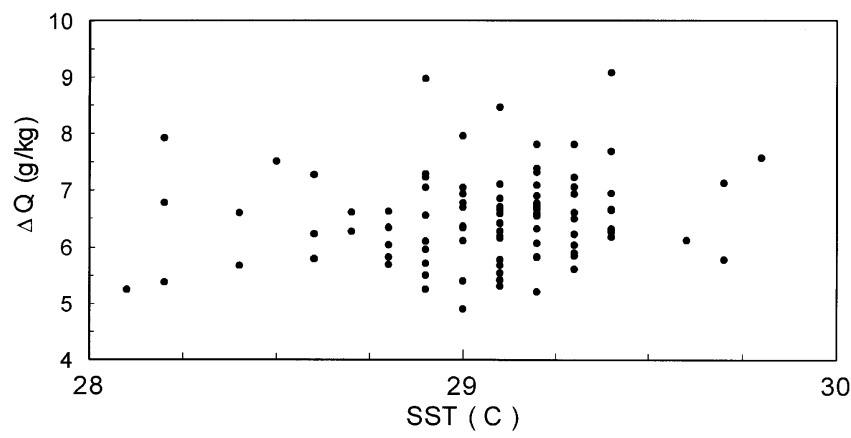

Figure 7. The variation of mixing ratio difference $\Delta Q$ $\left(Q_{s}(\mathrm{SST})-Q_{a}\right)$ with SST.

temperature around $28^{\circ} \mathrm{C}$ (this can be seen from the Clausius-Clapeyron relation). If the surface layer of the atmosphere is strongly coupled to the underlying ocean, we expect the amount of water vapor in the air to increase proportionately as SST increases. One measure of the water vapor in air is the mixing ratio defined as the amount of water vapor per unit mass of dry air, normally expressed as $\mathrm{g} / \mathrm{kg}$. The difference in the mixing ratios

$$
\Delta Q=Q_{s}-Q_{a},
$$

where $Q_{s}$ is the saturation mixing ratio at SST and $Q_{a}$ is the mixing ratio of the surface air, is shown in figure 7. $\Delta Q$ varies in 5 to $9 \mathrm{~g} / \mathrm{kg}$ range. There is no clearly discernible dependence of the mixing ratio difference on SST. In the bulk aerodynamic formulae for calculating the surface latent heat flux, $\Delta Q$ is taken as a function of SST. In the SST range encountered during the Pilot experiment, there is no clear evidence for such a dependence and a constant value around $6.5 \mathrm{~g} /$ $\mathrm{kg}$ describes the variation pretty well.

Moist static energy, usually denoted by $h$, is a measure of the total energy of the air (neglecting the kinetic energy which is a very small fraction of $h$ and is an important thermodynamic parameter in tropics, particularly in problems involving moist convection. Another thermodynamic parameter important in deep convection is the equivalent potential temperature $\theta_{e}$. 


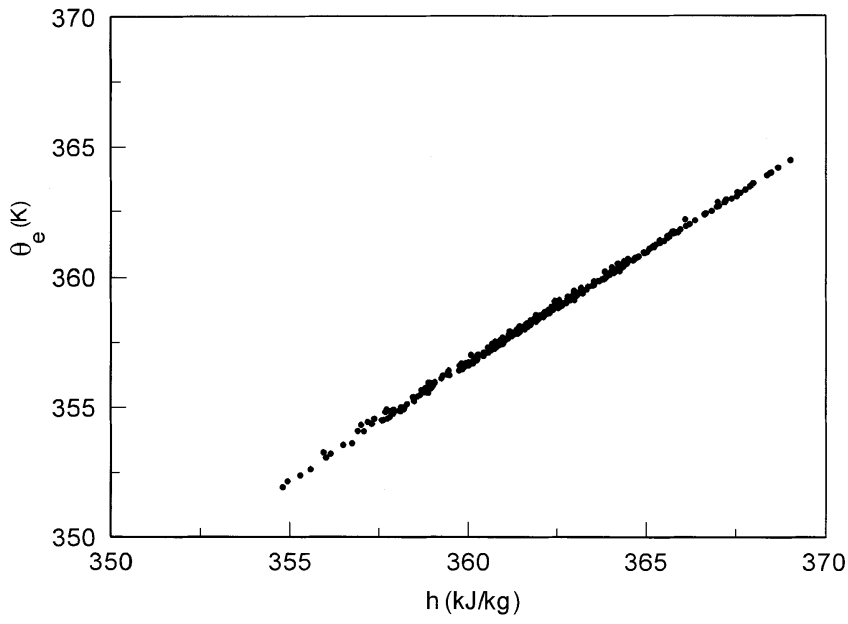

Figure 8. Scatter plot of equivalent potential temperature $\left(\theta_{e}\right)$ versus moist static energy $h$.

$\theta_{e}$ is the potential temperature attained by a parcel of moist air when it is lifted in the atmosphere pseudomoist adiabatically, condensing all the moisture and then brought back to $1000 \mathrm{mb}$ dry adiabatically. $\theta_{e}$ is a measure of the total entropy of the moist air. Now, $h$ is defined by

$$
h=C_{p} T+g z+L q,
$$

where $C_{p}$ is the specific heat of air at constant pressure, $T$ is the air temperature, $L$ is the latent heat of evaporation, $q$ is the water vapor mixing ratio, $g$ is acceleration due to gravity and $z$ is the height above the sea level. Scatter plot of $\theta_{e}$ versus $h$ (both based on psychrometer data) is shown in figure 8 . The moist static energy was more than $350 \mathrm{~kJ} / \mathrm{kg}$ with a mean around $355 \mathrm{~kJ} / \mathrm{kg}$ (during rains, the temperature and humidity were not systematically collected and $h$ could have been lower than $350 \mathrm{~kJ} / \mathrm{kg}$ due to downdrafts). It is observed from figure 8 that $\theta_{e}$ and $h$ are very strongly (linearly) correlated. $\theta_{e}$ in the study area mainly varied between $352 \mathrm{~K}$ and $365 \mathrm{~K}$. The corresponding range in the warm pool of the Pacific Ocean is $345 \mathrm{~K}$ to $362 \mathrm{~K}$ (Godfrey et al 1998). Thus, SST and surface energies in the Bay of Bengal were among the highest in the tropics during the Pilot experiment. It is said that $\theta_{e}$ values greater than $345 \mathrm{~K}$ are conducive for deep convection in tropics (Betts and Ridgway 1989), and that found in the south Bay of Bengal is larger than this critical value. Therefore, the southern Bay of Bengal provides the ideal breeding ground for the formation and intensification of tropical disturbances.

\subsection{Radiation}

Figure 9 shows the incoming global (hemispheric) solar radiation along with its daily mean, and the daily average incoming global longwave radiation. The daily average solar radiation varied in the range $80 \mathrm{~W} / \mathrm{m}^{2}$

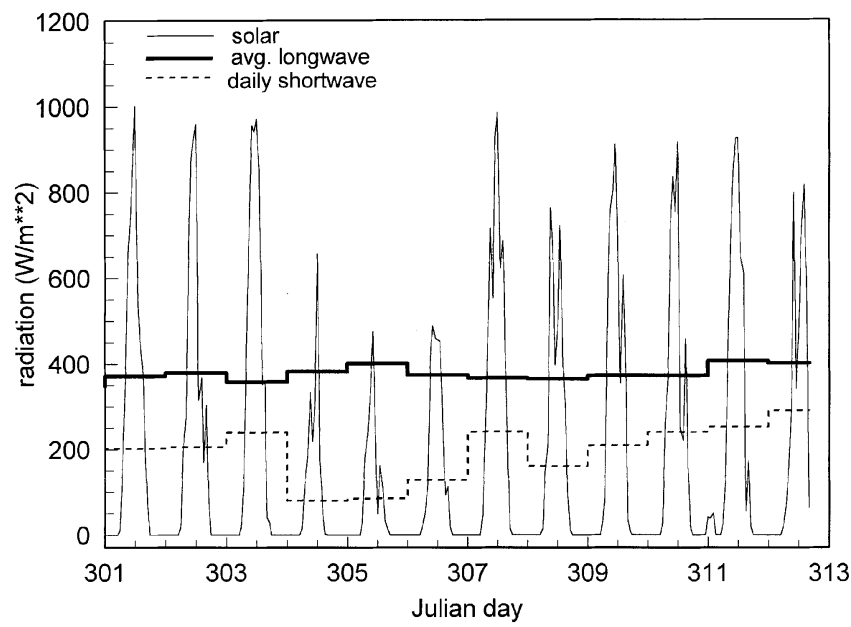

Figure 9. Global hemispheric incoming radiation.

to $250 \mathrm{~W} / \mathrm{m}^{2}$. The minimum average value of $80 \mathrm{~W} /$ $\mathrm{m}^{2}$ was observed on days 304 and 305 (convective days), and the maximum value of $250 \mathrm{~W} / \mathrm{m}^{2}$ on days 307 and 311 . The average incoming shortwave radiation for the entire twelve day period is $188 \mathrm{~W} / \mathrm{m}^{2}$. The downward longwave radiation fluctuates in a narrower range of 350 to $400 \mathrm{~W} / \mathrm{m}^{2}$ with a mean around $375 \mathrm{~W} /$ $\mathrm{m}^{2}$. Generally, the downward longwave radiation increased in the presence of deep clouds, reaching as high as $425 \mathrm{~W} / \mathrm{m}^{2}$ for short time duration when thick cumulonimbus clouds were overhead. The upward longwave radiation calculated from the SKINSST is between 445 and $450 \mathrm{~W} / \mathrm{m}^{2}$, virtually constant compared to the fluctuations in the incoming radiation. Thus, the net longwave radiation at the surface varied from $25 \mathrm{~W} / \mathrm{m}^{2}$ to $100 \mathrm{~W} / \mathrm{m}^{2}$ (positive upwards) with an average of $75 \mathrm{~W} / \mathrm{m}^{2}$.

\subsection{Mixed layer height}

The atmospheric mixed layer is that part of the atmosphere which continuously interacts with the underlying surface and its properties are strongly coupled to that of the surface below. The mixed layer height (MLH) is an important parameter because the effects of the surface are not directly felt above this layer unless convective clouds are present. MLH is inferred from the vertical profile of the virtual potential temperature $\theta_{v}$ defined by,

$$
\theta_{v}=T(1000 / p)^{\gamma}\left(1 .+0.608^{*} q\right),
$$

where $T$ is the temperature $(\mathrm{K}), p$ is pressure $(\mathrm{mb})$ and $q$ is the water vapor mixing ratio $(\mathrm{kg} / \mathrm{kg})$ and $\gamma=0.28$. A constant value of $\theta_{v}$ with height implies a neutrally stable atmosphere, whereas, increasing (decreasing) $\theta_{v}$ with height means that the atmosphere is stable (unstable) for dry adiabatic displacements. In figure 10, we show typical vertical profiles of $\theta_{v}$ taken in the afternoon (1430 hours). All the three soundings show a thin layer near the surface where $\theta_{v}$ rapidly 


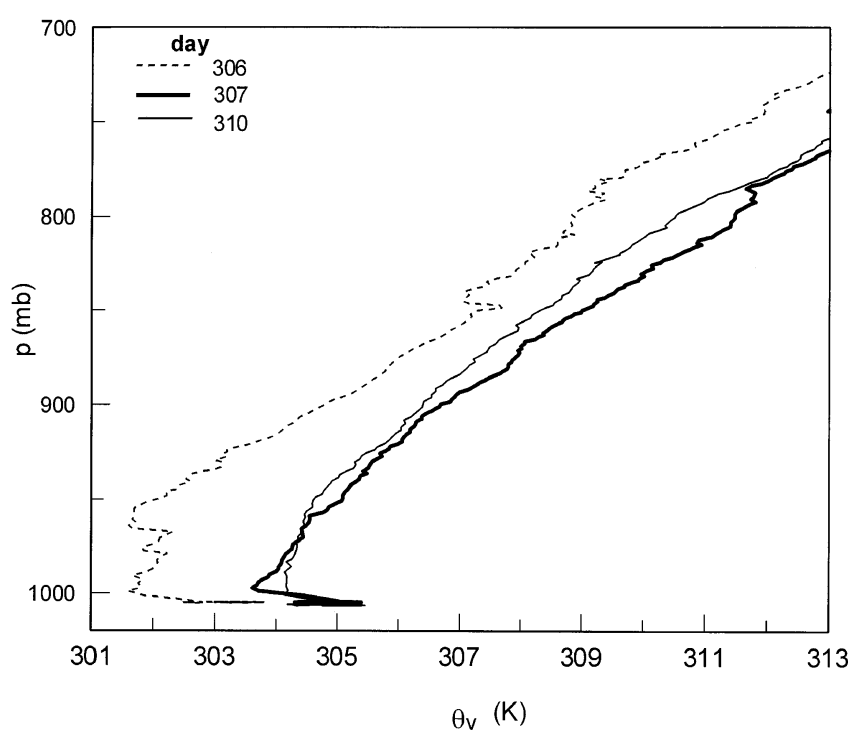

Figure 10. Vertical profiles of the virtual potential temperature $\theta_{v}$ for three afternoon (09 UTC) soundings.

decreases with height. This is the convectively unstable super adiabatic layer (called the surface layer), and air parcel will accelerate if displaced vertically. Above the surface layer, the nature of the profiles differ. On day 306 , the ship was at $10^{\circ} \mathrm{N}, 87^{\circ} \mathrm{E}$ and a large deep cloud band had passed over this area the previous day, the area was still cloudy and the average short wave radiation for the day was about $130 \mathrm{~W} / \mathrm{m}^{2}$ (figure 9). The atmospheric cooling caused by convection is clearly seen on day 306 . On this day, $\theta_{v}$ decreased sharply immediately above the surface and then there is a region where it remained nearly constant (well mixed layer). This extended up to $950 \mathrm{mb}$ and then $\theta_{v}$ started increasing almost monotonically with height. The profile of $\theta_{v}$ for the day 307 is distinctly different where it decreased initially, reached a minimum, and then started increasing. There is no well mixed layer. On day $310, \theta_{v}$ was constant in a shallow layer of about $20 \mathrm{mb}$ deep and then gradually started increasing, the slope of $\theta_{v}$ changed around $950 \mathrm{mb}$, however, there was no sudden jump/increase in $\theta_{v}$ (capping inversion) that marks the mixed layer top in tropics. There is no substantial variation in the nature of the profiles above $900 \mathrm{mb}$.

The height from the surface up to which the well mixed layer extends is taken as the mixed layer height here. The profiles during the Pilot experiment very rarely showed a layer where $\theta_{v}$ strictly remained constant and some amount of subjectivity is involved in determining the mixed layer height. The uncertainty is 50 meters at most. Figure 11 shows the variation of the mixed layer height during the Pilot experiment along with the height of the surface layer. It is observed from figure 11 that the height of the super adiabatic layer varied from about 20 meters to 100 meters, and that of the mixed layer from 50 meters to 900 meters with a mean between $400 \mathrm{~m}$ and $600 \mathrm{~m}$.

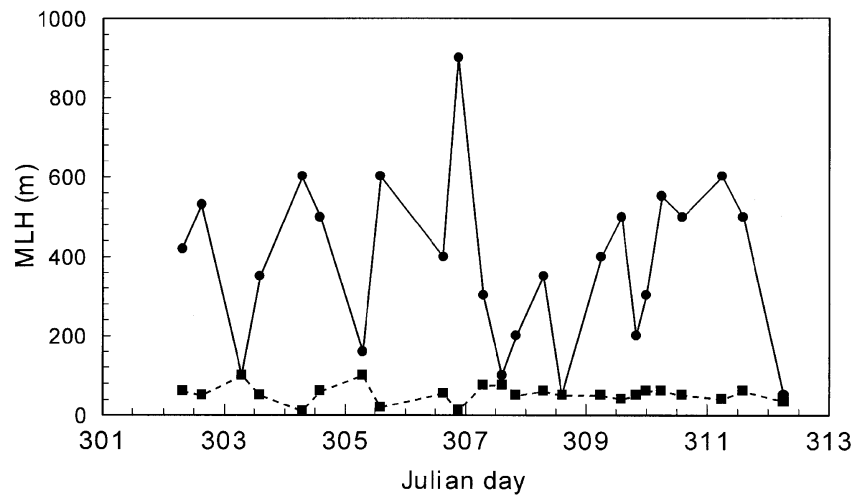

Figure 11. Variation of the mixed layer and surface layer heights during BOBMEX-Pilot.

The height of the mixed layer over other tropical oceans is about 500 meters (LeMone 1978) and for the majority of the time, that observed during the Pilot experiment is in good agreement with this.

\section{Discussion}

As stated in the introduction, the frequency of occurrence of deep convective systems over the Bay of Bengal is among the highest in the world. A mean SST of $29^{\circ} \mathrm{C}$ and high values of $h$ and $\theta_{e}$, make the surface conditions very favorable for the occurrence of deep convection (Bhat et al 1996). High values of $h$ and $\theta_{e}$ are due to very warm SST. Thus, the basic issue is the physical mechanisms that maintain high SSTs in the Bay of Bengal. SST is the outcome of energy balance, where radiation, sensible and latent heat fluxes and advection are main contributors. Observations carried out during the Pilot experiment suggested that among other factors, the atmospheric and oceanic mixed layers can have an important role in controlling SST. Here we consider one specific case, namely, day 307. For the 12 day period under study, the solar radiation was the highest on this day (figure 9). SST increased by nearly a degree centigrade, air temperature increased by more than a degree centigrade (figure 5(a)) and relative humidity decreased below $80 \%$ during the forenoon. Wind speeds were moderate (less than a meter per second to about $4 \mathrm{~m} / \mathrm{s}$ ). A rough estimation of the surface heat fluxes indicated that the sensible heat flux was between 10 and $20 \mathrm{~W} / \mathrm{m}^{2}$, and the latent heat flux varied from 30 to $100 \mathrm{~W} / \mathrm{m}^{2}$. The observed MLH was less than 100 meters and therefore, the heat and moisture fluxes from the ocean were trapped in a shallow atmospheric layer near the surface. The corresponding afternoon CTD profile (data not shown here) showed the formation of a warm water layer of about $5 \mathrm{~m}$ deep due to intense short wave heating. Around noon time, winds were very low (figure 4(a)) and this helped in the formation of a thin, warm and stable 
layer in the ocean. Thus, very shallow atmospheric and oceanic mixed layers together restricted the vertical diffusion of heat and led to rapid increases in the air temperature and SST. As the depth of the warm layer of water was small, SST rapidly decreased once the intensity of solar radiation decreased. This example shows that shallow mixed layers can be very effective in trapping the heat energy from shortwave radiation in shallow layers. Further studies are required to understand the precise role and contribution of the mixed layers in controlling the SST evolution.

A related question is, what caused the very shallow mixed layer on day 307. Except in regions of large scale low level convergence, subsidence prevails in the atmosphere and the subsidence tends to decrease the mixed layer depth by 300 to 400 meters per day (Betts and Ridgway 1989). The surface fluxes on the other hand tend to push the mixed layer upwards, and the actual height of the mixed layer is decided by the balance between these two opposing processes. On day 307, the surface fluxes were reasonably high (perhaps that could maintain a mixed layer height around 400 to 500 meters under normal conditions), still we see practically no mixed layer. Therefore, a very strong subsidence must have been prevailing to push down the mixed layer top to almost close to the surface. This subsidence might have been caused by a disturbance that had intensified near the Tamilnadu coast on day 307 . Thus, while an intense convective system cools the ocean due to increased surface fluxes and reduced solar radiation directly under it, it can aid the enhancement of SST in the surrounding regions where subsidence induced by it prevails.

We have seen that there is no systematic dependence of $\Delta Q$ on SST (figure 7). Similarly, the sea air temperature difference $\Delta T$ also varies in a wide range (figure $5(\mathrm{~b})$ ). $\Delta Q$ or $\Delta T$ depend mainly on SST if some sort of quasi-equilibrium prevails between the ocean and the air in the mixed layer. Such quasiequilibrium is possible provided the synoptic conditions persist for a sufficiently long time. We have seen that during the Pilot experiment, synoptic conditions changed and both convective and clear sky conditions were present. Following rain, the surface humidity decreased due to drier air being brought down to the surface by the convective downdrafts. Similarly, the air temperature decreased by as much as $4^{\circ} \mathrm{C}$ whereas SST remained almost unaffected. After the rains stopped, the surface air properties slowly recovered to the pre-rain conditions. Thus, for the same SST, a wide range of $\Delta Q$ and $\Delta T$ are encountered. A clearer picture might emerge if the data are stratified according to the prevailing synoptic conditions.

It is observed that the moist static energy $h$ and the equivalent potential temperature $\theta_{e}$ are linearly correlated with comparable magnitudes. However, a linear relationship between $h$ and $\theta_{e}$ is not obvious.
Though both are thermodynamic parameters, $h$ is the measure of total energy and $\theta_{e}$ is the measure of the total entropy of the air, and are calculated in different fashions. For example, in the calculation of $h$, surface sensible heat, latent heat and potential energy are added together. On the other hand, $\theta_{e}$ involved integrating the properties of an air parcel along a moist pseudoadiabat with the pressure varying from that corresponding to the surface value to less than $100 \mathrm{mb}$. Further studies are needed to understand $h$ and $\theta_{e}$ relationship over other oceans and also over the Bay of Bengal under different synoptic conditions.

\section{Conclusion}

The Pilot experiment for BOBMEX was very successfully conducted and useful data in the southern Bay of Bengal during a cyclone period have been collected. It is observed that the SSTs were high, surface air was warm and moist, and the surface air moist static energy was among the highest observed over the tropical oceans. The mean sea air temperature difference was about $1.25^{\circ} \mathrm{C}$ and the sea skin temperature was cooler than bucket SST by $0.5^{\circ} \mathrm{C}$. The two commonly used thermodynamic parameters, namely the moist static energy and the equivalent potential temperature are linearly correlated. The atmospheric mixed layer was shallow, fluctuated in response to synoptic conditions and sometimes shallower than 100 meters. The mixed layer dynamics can play an important role in controlling SSTs in the Bay of Bengal.

\section{Acknowledgements}

This work was supported by a grant from the Department of Science and Technology, New Delhi and we thank the agency for the support. We thank Antarctica Study Centre (ASC), Goa (a unit of Department of Ocean Development) for making available the ship along with its facilities for the Pilot experiment. We thank Sri D R Sikka for the encouragement, invaluable comments and suggestions on the scientific scope and objectives of ICRP and BOBMEX. The India Meteorological Department (IMD) provided the hydrogen gas for filling the balloons and faxed daily INSAT-1D visible images to the ship during the cruise and we sincerely thank IMD. National Institute of Oceanography Goa, is the other principal participating organization in the Pilot experiment, and it has been a pleasure to work with Sri L V G Rao, Dr. Ramesh Babu and Dr. V S N Murty. We thank them all. Prof. Sulochana Gadgil and Prof. J Sreenivasan have helped us from the very early stages of this project and we thank them for the support and 
encouragement received. We thank Dr. D Sengupta, for initiative, several discussions and helpful suggestions. Mr. J V S Raju, Mr. C P Chandrasekhara, Mr. G Ravi, Mr. Retish Senan and Mr. Saji Varghese worked day and night in the manual data collection on board the ship and we thank them all for an excellent job done.

\section{References}

Betts A K and Ridgway W 1989 J. Atmos Sci. 46 2621-2641 Bhat G S, Srinivasan J and Gadgil S 1996 J. Meteor. Soc. Japan 74 155-166

Bradley E F, Coppin P A and Godfrey J S 1991 J. Geophys. Res. 96 3375-3389

Godfrey J S, Houze R A Jr, Johnson R H, Lukas R, Redelsperger J -L, Sumi A and Weller R 1998 J. Geophys. Res. 103 14395-14450

Kalsi S R 2000 Proc. Indian Acad. Sci. (Earth Planet. Sci.), (this issue)
LeMone M L, Wyngaard J C (ed.), Proc. Workshop on the Planetary Boundary Layer, 14-18 August, 1978 (American Meteorological Society) 182-234

Mohanty U C and Das S 1986 Proc. Indian Natn. Sci. Acad. 52 625-640

Moshonkin S M and Harenduprakash L 1991 Okeanologiya 31(3) 384-394

Murty V S N, Sarma Y V B and Rao D P 1996 Proc. Ind. Acad. Sci. (Earth Planet. Sci.) 105 41-61

Premkumar K, Ravichandran M, Kalsi S R, Sengupta D and Gadgil S 2000 Curr. Sci. 78 323-330

Rao R R, Basil Mathew and Hareeshkumar P V 1993 Deep-Sea Res. 40 1647-1672

Saha K R and Saha S 1988 Mon. Weather Rev. 116 242-255

Sanilkumar K V, Mohankumar N, Joseph M X and Rao R R 1994 Deep-Sea Res. 41(10) 1569-1581

Sarma Y V B, Seetaramayya P, Murty V S N and Rao D P 1997 Boundary Layer Met. 82 517-526

Slutz R J, Lubker S J, Hiscox J D, Woodruff S D, Jenne R L, Joseph D H, Steurer P M and Elms J D 1985 COADS: Comprehensive Ocean Atmosphere Data Set. Release 1, 262 pp.

Sikka D R and Sanjeeva Rao P 2000 Proc. Indian Acad. Sci. (Earth Planet. Sci.) (this issue). 